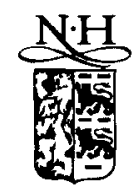

ELSEVIER

\title{
Information, trading, and volatility
}

\author{
Charles M. Jones, Gautam Kaul*, Marc L. Lipson \\ School of Business Administration, University of Michigan, Ann Arbor, MI 48109-1234, USA
}

(Received October 1992; final version received November 1993)

\begin{abstract}
We examine the effects of trading and information flows on the short-run behavior of stock prices by comparing the behavior of stock return volatility during trading and nontrading periods. We define nontrading periods as periods when exchanges and businesses are open but traders endogenously choose not to trade. After correcting for the bid/ask bounce and stickiness in quotes, we find that a large proportion of daily stock return volatility occurs without trades, especially for large firms. Furthermore, we provide new evidence that public (versus private) information is the major source of short-term return volatility.
\end{abstract}

Key words: Information; Trading; Return volatility; Market micro-structure JEL classification: $\mathrm{G} 14$

\section{Introduction}

To understand the effects of trading and information flows on short-run stock return volatility, a growing literature has examined the effects of market closures

\footnotetext{
* Corresponding author.
}

We appreciate the comments and suggestions made by Michael Barclay, Jennifer Conrad, David Denis, Thomas George, Mark Grinblatt, Richard Roll, Atulya Sarin, Eduardo Schwartz, Bill Schwert, Paul Seguin, Steve Slezak, Sheridan Titman, Jerry Warner, and seminar participants at UCLA, the University of Michigan, the University of Rochester, the University of South Carolina, and the Virginia Polytechnic Institute. Special thanks are due to Kenneth French, the referee as well as to Seha Tinic, the discussant of this paper at the Western Finance Association Meetings, San Francisco, June 1992, and Campbell Harvey, for detailed comments and suggestions. We also thank Patti Lamparter and Stacy Ferry for preparing the manuscript. Part of this research was conducted while Charles Jones was visiting at Northwestern University. Partial funding for this research was provided by the School of Business Administration, Univcrsity of Michigan. 
on stock return dynamics. In an important study, French and Roll (1986) compare the behavior of volatility when exchanges are open to its behavior when exchanges are closed and demonstrate that ' $\ldots$ on an hourly basis, the variance of returns when the exchanges are open is between 13 and 100 times larger, depending on the non-trading period being considered' (other early empirical studies include Fama, 1965; Granger and Morgenstern, 1970; Oldfield and Rogalski, 1980; Christie, 1981). With the availability of diverse new data, empirical researchers have since conducted more detailed investigations of the behavior of stock returns during trading and nontrading periods in the U.S. and other countries. ${ }^{1}$ Similarly, theoretical researchers have developed strategic and competitive models of trading to explain the high (low) volatilities during exchange trading (nontrading) periods (e.g., Admati and Pfleiderer, 1988; Foster and Viswanathan, 1990; and Slezak, 1992).

In this paper, we use a new approach to analyze the effects of trading and the flow of public and private information on short-run volatility. Specifically, we define nontrading periods as periods when exchanges and businesses are open but traders endogenously choose not to trade. Consequently, our trading and nontrading periods are comparable in two critical ways. First, since nontrading periods are not predictable, the information-gathering and trading activities of traders are not conditioned on their ability to trade. Second, since businesses are open, the activities which generate and release public information are unchanged. Thus, we can directly measure the relation between trading and volatility and, since volatilities in this analysis are likely to measure the (random) arrival of information without the confounding effects of agents adjusting their information-acquisition behavior, we can shed light on the relation between information flows and volatility. In contrast, nontrading periods in previous studies are predictable, exogenously-determined exchange closings, and the production and release of private and public information are likely to be altered during these periods. ${ }^{2}$

We measure the relation between trading and volatility by comparing the return variances of nontrading and trading periods. We calculate nontrading to trading variance ratios for weekends (the ratio of the variance of returns from Friday's close to Monday's close when Mondays have no trades to the variance when Mondays have trades) and weekdays (the ratio of the variance of returns

\footnotetext{
${ }^{1}$ Studies of U.S. data include Amihud and Mendelson (1987), Foster and Viswanathan (1993a), and Stoll and Whaley (1990). Studies of non-U.S. data include Amihud, Mendelson, and Murgia (1990), Barclay, Litzenberger, and Warner (1990), and Amihud and Mendelson (1991).

${ }^{2}$ The study that is perhaps closest to our paper in design is the investigation of foreign exchange volatility during exchange (rading versus nontrading hours by Harvey and Huang (1991). Given the worldwide trading of foreign exchange, the foreign exchange 'market' is effectively open 24 hours a day. Hence, even during the nontrading periods of the Chicago Mercantile Exchange, there is trading on other international exchanges.
} 
on weekdays that have no trades to the variance of weekdays that have trades). Following Jones and Kaul (1993), we adjust for several biases present in variance ratios of individual security returns. Specifically, we show that while the use of transaction prices causes variance ratios to be systematically biased, the use of bid/ask quotes could also lead to potential biases because market makers adjust quotes infrequently (see Geraghty, 1992). We provide estimates of variance ratios that correct for both the bid/ask bounce in transaction returns and the stickiness of quotes in quote-based returns.

Our empirical analysis of NASDAQ-NMS stocks over the 1984-1991 period shows that a substantial proportion of daily stock return volatility occurs without trading. After correcting for the bid/ask bounce and stickiness in quotes, we find that the nontrading to trading variance ratios vary between 0.20 and 0.30 , or that between $20 \%$ and $30 \%$ of daily price movements occur in the absence of trading on days when exchanges and businesses are open. In addition, the variance ratios for both weekdays and weekends increase monotonically with firm size. For example, the median weekend nontrading to trading variance ratio for the largest firms is about $50 \%$ larger than for the smallest firms. Therefore, a substantially higher fraction of price movements of large versus small firms occurs without trades.

We also use our nontrading and trading classification to assess the relative importance of public and private information in determining short-run volatility. To do this, we consider two possible scenarios. First, assume that public information is produced at a constant rate on days when exchanges and businesses are open and is incorporated into asset prices without trading. Also, assume that the arrival of private information is stochastic and that trading is necessary for such information to influence prices. This scenario has been explicitly or implicitly assumed in several studies (see, for example, French and Roll, 1986; Hasbrouck, 1991). Under these circumstances, our nontrading to trading variance ratios have a straightforward economic interpretation: they are measures of the relative importance of public information in determining volatility.

Alternatively, we assume that private information is a small (or negligible) fraction of the total flow of information and that public information might also lead to trading. Clearly, there are numerous corporate and macroeconomic public announcements every day, and there is ample evidence that such announcements arc associated with surges in trading. Moreover, several recent theoretical papers have shown that unexpected public announcements will lead to trading (see, for example, Foster and Viswanathan, 1993b; Kim and Verrecchia, 1991). In fact, Harris and Raviv (1993) show that even without any private information (and therefore without any information asymmetry) trading can occur due to differences in opinion (see also Varian, 1989). Under this alternative hypothesis, the nontrading to trading variance ratios have a different interpretation: they measure the relative (random) flow of public information on nontrading and trading days. 
It is important to note that these extremely stylized hypotheses represent two of many potential patterns of information flow. In reality, it is likely that the flow of public information, the acquisition of private information, and trading interact in more complicated ways. Nevertheless, since these two assumptions are important benchmarks, examining their implications and gauging their relative merit provides valuable insight into the relation between information flows and volatility. For example, if the evidence supports the first hypothesis, our results on the relation between trading and volatility would suggest that while public information is a significant determinant of volatility, private information still plays a primary role.

To distinguish between the two hypotheses, we examine market microstructure characteristics within the context of our definition of nontrading. First, we use the approach in George, Kaul, and Nimalendran (1991) to determine the relative size of the adverse-selection component of the bid/ask spread in our sample of securities. This analysis provides insight into the importance of private information (information asymmetry) in asset markets (see, for example, Glosten and Milgrom, 1985). We find that the adverse-selection component is a small fraction (12-15\%) of quoted spreads. Second, and more importantly, we compare bid/ask spreads of securities on nontrading and trading days. If private information plays a dominant role in determining volatility, the bid/ask spreads on nontrading days should be smaller than spreads on trading days (see Easley and O'Hara, 1992). Conversely, if public information is the primary determinant of volatility, the adverse-selection component of spreads (and, ceteris paribus, quoted spreads themselves) should not only be small, but also equal, on trading and nontrading days. We find that the differences between the average bid/ask spreads on trading and nontrading days are economically insignificant, regardless of the cross-sectional characteristics of the firms in our sample.

Finally, we reexamine the effect of closed exchanges on volatility using our definition of nontrading. We show that either (a) public information is the primary determinant of volatility or (b) private information-gathering over a weekend is reduced by exactly the reduction in the flow of public information over a weekend. Given the implausibility of the symmetry in the flows of public and private information implied by (b), we conclude that private information is a small fraction of the total flow of information. Although the evidence from our individual tests could be consistent with more complicated models of information and trading, our empirical results taken together suggest that public (as opposed to private) information is the main determinant of short-term volatility.

In Section 2 we describe the data and the statistical procedures used to compute the nontrading to trading variance ralios; this section also contains a brief discussion of the potential biases in variance ratios of individual securities. We present and analyze our evidence on the relation between trading and volatility in Section 3. Section 4 focuses on the relation between information flows and volatility; we interpret our earlier results and present additional evidence. Section 5 concludes the paper. 


\section{Data and methodology}

\subsection{Data description}

We use the Center for Research in Security Prices (CRSP) daily master file for NASDAQ-NMS-firms to compute security returns. Following its inception in 1982, trading on the NMS was initially limited to only the most actively-traded stocks. Hence, we use data from January 1984 to December 1991. We break up the eight-year sample period into 15 six-month (126-trading-day) subperiods and include all firms (except those that experience stock splits during a particular subperiod) that have an unbroken series of closing bid/ask quotes. Since the NASDAQ-NMS tapes do not have any bid/ask quotes for February 1986, we drop this month and lose the last (sixteenth) subperiod because it is shorter than a 126-trading-day interval.

We use the NMS sample because CRSP reports daily closing 'inside' bid/ask quotes on both trading and nontrading days. This procedure is distinctly different from the one used for NYSE/AMEX securities for which CRSP reports last-trade transaction prices on trading days, but the average of closing bid and ask quotes when no trades occur. We demonstrate in Section 2.5 that it is important to use closing quotes to calculate returns for both trading and nontrading days.

A six-month sampling interval is chosen primarily to maximize the number of firm-observations; lengthening the subperiods results in the loss of a substantial number of firms because they do not have an unbroken series of daily quotes. Including such firms in the sample is particularly important for our study because these firms are also the ones that experience frequent nontrading. Another advantage of the subperiod analysis is that we can study the time-series patterns, if any, in the variance ratios. We sort all the sampled securities into five portfolios based on market value (number of shares outstanding times price per share) at the beginning of each subperiod. We use firm size as a proxy for the potentially different rates of acquisition and flow of information across different securities. All returns used in our analysis are continuously compounded.

\subsection{Some descriptive statistics}

Table 1 reports some summary statistics for the firms in our overall sample, including market value (in millions of dollars), the average of closing bid and ask prices, dollar volume, number of transactions, and the percent bid/ask spread which is calculated as $\left(P_{A}-P_{B}\right) / \frac{1}{2}\left(P_{A}+P_{B}\right)$, where $P_{A}$ and $P_{B}$ are the closing ask and bid prices. All reported numbers are based on daily observations and are the averages of the individual-firm estimates over the entire 1984-1991 sample period. 
Table 1

Daily descriptive statistics of NASDAQ-NMS stocks, 1984-1991

This table contains summary statistics on market value (number of shares outstanding times price per share), the average of closing bid and ask prices, dollar volume, number of transactions, and quoted spreads. The quoted spread, reported in percent, is calculated as $\left(P_{A}-P_{B}\right) / \frac{1}{2}\left(P_{A}+P_{B}\right)$. where $P_{A}$ and $P_{B}$ are the ask and bid prices at the end of each day. The descriptive statistics are based on daily data and are reported for all securities and for securities belonging to five portfolios formed by rankings of market value of equity outstanding at the beginning of each six-month (126trading-day) period. The individual-firm statistics are averaged across firms within each portfolio (and across all firms in the sample) for the entire 1984-1991 sample period. The second column reports the total number of observations for each port folio and for the entire sample of firms used to calculate the summary statistics.

\begin{tabular}{|c|c|c|c|c|c|c|}
\hline ....... & $-\ldots$ & $\cdots .$. & $\ldots . . . .$. & $\cdots$ & $\cdots$ & - \\
\hline Portfolio & $\begin{array}{l}\text { No. of } \\
\text { observations }\end{array}$ & $\begin{array}{l}\text { Market } \\
\text { value } \\
\text { (in million } \\
\text { dollars) }\end{array}$ & $\begin{array}{l}\text { Average of } \\
\text { bid/ask price } \\
\text { (in dollars) }\end{array}$ & $\begin{array}{l}\text { Dollar } \\
\text { volume } \\
\text { (in million } \\
\text { dollars) }\end{array}$ & $\begin{array}{l}\text { No. of } \\
\text { transactions }\end{array}$ & $\begin{array}{l}\text { Quoted } \\
\text { spread } \\
(\%)\end{array}$ \\
\hline 1 (smallest) & 5495 & 8.913 & 4.894 & 24.248 & 4.273 & 11.647 \\
\hline 2 & 5492 & 21.760 & 8.133 & 70.201 & 7.845 & 6.686 \\
\hline 3 & 5490 & 43.478 & 11.187 & 159.053 & 12.390 & 4.678 \\
\hline 4 & 5492 & 95.947 & 16.553 & 406.114 & 19.661 & 3.192 \\
\hline 5 (largest) & 5483 & 474.834 & 28.969 & 2402.418 & 52.754 & 1.834 \\
\hline All firms & 27452 & 128.866 & 13.941 & 611.789 & 19.173 & 5.609 \\
\hline
\end{tabular}

The numbers in Table 1 reflect the fairly diverse sample of securities used in this study. For example, average market values range between $\$ 9$ million (portfolio 1) and \$475 million (portfolio 5). Since Jones, Kaul, and Lipson (1993) show that the volatility of daily returns is more closely related to the number of transactions than to volume, we report both average volume and number of transactions for securities in all portfolios. An important statistic is the quoted spread, which ranges between $1.83 \%$ and $11.65 \%$ and averages $5.61 \%$ for all firms in the sample. These spread estimates suggest that measurement errors in stock prices are likely to cause substantial spurious volatility in transaction returns because this volatility is directly related to the square of the proportional spread (see the Appendix). The spread estimates, in conjunction with the market values, also suggest that although our samplc contains a wide range of securitics, large firms are not well represented. For example, the average spread of $5.61 \%$ is substantially higher than the average of $2.82 \%$ for NYSE/AMEX firms at the end of 1988 (Keim, 1989, table 6, p. 96), mainly because the large firms on the NYSE with spreads of less than $1.00 \%$ are not represented in the NASDAQ sample. However, these large firms constitute approximately $25 \%$ of the NYSE/ AMEX sample used by Keim (1989); the remaining 75\% of his firms (about 1,800 ) display characteristics that are similar to the characteristics of the firms in our sample. 
Table 2

Relative frequency of nontrading by day-of-the-week for NASDAQ-NMS stocks, 1984-1991

The estimates are calculated for each day of the week as the ratio of the number of nontrading days to the total number of days when the market is open. The ratios are calculated for every firm that has at least one trading day and one nontrading day for both Mondays and the Tuesday-Friday interval during a six-month (126-trading-day) subperiod. We report the averages of individual-firm ratios across all subperiods for securities belonging to five portfolios formed by rankings of market value of equity outstanding at the beginning of each subperiod. The sccond column reports the total number of observations for each portfolio over all subperiods used to calculate the average nontrading frequencies, and the third column shows the average market values of the securities.

\begin{tabular}{|c|c|c|c|c|c|c|c|}
\hline \multirow[b]{2}{*}{ Portfolio } & \multirow{2}{*}{$\begin{array}{l}\text { No. of } \\
\text { observations }\end{array}$} & \multirow{2}{*}{$\begin{array}{l}\text { Market } \\
\text { value } \\
\text { (in million } \\
\text { dollars) }\end{array}$} & \multicolumn{5}{|c|}{ Relative frequency of nontrading } \\
\hline & & & Monday & Tuesday & Wednesday & Thursday & Friday \\
\hline 1 (smallest) & 4505 & 8.213 & 0.317 & 0.309 & 0.312 & 0.314 & 0.318 \\
\hline 2 & 3430 & 20.036 & 0.245 & 0.229 & 0.239 & 0.237 & 0.243 \\
\hline 3 & 2479 & 40.231 & 0.211 & 0.196 & 0.198 & 0.199 & 0.210 \\
\hline 4 & 1757 & 88.811 & 0.184 & 0.171 & 0.177 & 0.178 & 0.182 \\
\hline 5 (largest) & 707 & 275.198 & 0.145 & 0.129 & 0.133 & 0.130 & 0.136 \\
\hline
\end{tabular}

\subsection{Frequency of nontrading}

Since we are interested in the behavior of stock return volatility on nontrading and trading days, we sample securities from each market value portfolio that have at least one nontrading day and one trading day for both Mondays and the Tuesday-Friday interval during a six-month subperiod. ${ }^{3}$ Table 2 contains the relative frequencies of nontrading for these securities by day of the week to evaluate whether there are any systematic patterns in nontrading during the week. All estimates are averages of individual-firm values over all subperiods and are reported for all portfolios. The second column shows the total number of firm-observations used to calculate the reported averages. Note that the number of small firms is much greater than the number of large firms. This is not surprising because during a particular subperiod we require each security to have at least one nontrading Monday and one nontrading day during the Tuesday-Friday interval. As a consequence, the average market values of firms in each of the five portfolios drop in comparison to the original sample,

\footnotetext{
${ }^{3}$ It is important to note that virtually none of the nontrading days in our sample are likely to have occurred due to trading halts. This is important because trading halts usually occur due to 'excessive' activity in a stock. Consequently, if a large proportion of our nontrading days were due to such halts, we would overestimate the volatility on nontrading days. However, King, Pownall, and Waymire (1991) show that trading halts typically last for less than two hours and almost never extend to the next day.
} 
particularly for firms in portfolio 5 (see column 3). Nevertheless, the range of average market values in Table 2 ( $\$ 8$ million to $\$ 275$ million) still covers the majority (about $70 \%$ ) of NYSE/AMEX stocks.

The estimates in Table 2 show that the frequency of nontrading is much higher for small firms: the proportions for portfolio 1 are more than twice the magnitudes for portfolio 5. Also, a wide range of nontrading frequencies is represented in the sample. However, within each portfolio there appears to be very little variation in the relative frequency of nontrading on different days of the week: formal $F$-tests cannot reject the hypothesis that nontrading for a security in a particular market-value portfolio occurs randomly during the week. This finding is encouraging from our perspective because it shows that nontrading is not a systematic phenomenon, limited to particular days of the week. Also, it provides some justification for treating all weekdays in the Tuesday-Friday interval as identical in calculating the 'weekday' nontrading and trading volatilities.

\subsection{The volatility ratios}

In this paper, we distinguish between Mondays and the rest of the days in the week on which exchanges and businesses are open because Mondays follow a two-day exchange-and-business holiday. We calculate nontrading and trading variances using a procedure similar to the one used by Schwert (1990). Specifically, we first estimate the following mean equation for each security's return in each subperiod:

$$
R_{i t}=\sum_{k=1}^{5} \alpha_{i k} D_{k t}+\varepsilon_{i t}
$$

where $R_{i t}$ is the return of security $i$ on day $t$ and the $D_{k t}$ 's are the five day-of-the-week dummies used to capture differences in expected returns (see, for example, French, 1980; Keim and Stambaugh, 1984). We do not distinguish between nontrading and trading days in the mean equation (1). The purpose of estimating (1) is to extract any expected return movements, and since days of the week are perfectly predictable we use the five dummies. Since nontrading (or trading) days are ex ante unpredictable, however, we do not condition on the nontrading and trading dummies in the mean equation.

The nontrading and trading volatility estimates for weekends (that is, Mondays) and weekdays (Tuesday-Friday) are obtained by estimating the following regression:

$$
\begin{aligned}
\hat{\varepsilon}_{i t}^{2}= & \sigma_{i N T M}^{2} D_{N T M t}+\sigma_{i T M}^{2} D_{T M t}+\sigma_{i N T T F}^{2} D_{N T T F t}+\sigma_{i T T F}^{2} D_{T T F t} \\
& +\sigma_{i D H}^{2} D_{I D H t}+\sigma_{i 3 D H}^{2} D_{3 D H}+v_{i t}
\end{aligned}
$$


where $\hat{\varepsilon}_{i t}^{2}$ is the squared residual from (1), the dummy variable coefficients $\sigma_{i N T M}^{2}$ and $\sigma_{i T M}^{2}$ measure the intercepts for nontrading and trading Mondays, the coefficients $\sigma_{\text {iNTTF }}^{2}$ and $\sigma_{i T T F}^{2}$ measure the daily nontrading and trading volatilities during the Tuesday-Friday interval, and $\sigma_{i 1 D H}^{2}$ and $\sigma_{i 3 D H}^{2}$ measure the volatilities during one-day and three-day (long weekend) holidays. Since oneday and three-day holidays occur fairly infrequently, we do not distinguish between nontrading and trading days following these holidays. Nevertheless, since these holiday returns are likely to have different distributional characteristics than either Monday or other weekday returns, we use separate dummy variables for the one-day and three-day holidays.

We use a two-step procedure to estimate (2): we first estimate (1), and then use the squared residuals, $\hat{\varepsilon}_{i t}^{2}$ 's, as the dependent variable in (2) (see Davidian and Carroll, 1987). We use ordinary least squares to estimate (2), which provides consistent estimators of the parameters (see Pagan and Schwert, 1990). The estimators, however, are not efficient. Given the large sample of securities, we do not use weighted least squares to estimate (2) for each security. ${ }^{4}$

We use the coefficient estimates of (2) to calculate the variance ratios for each security in each subperiod. The ratios of variances on nontrading and trading days when the exchanges are open are calculated for both weekends (that is, Mondays) and weekdays, and are denoted by $V_{1}$ and $V_{2}$, respectively, where

$$
V_{1}=\frac{\sigma_{i N T M}^{2}}{\sigma_{i T M}^{2}} \text { and } \quad V_{2}=\frac{\sigma_{i N T T F}^{2}}{\sigma_{i T T F}^{2}} .
$$

\subsection{Methodological issues}

There are methodological problems associated with the use of variance ratios for individual securities, particularly with high-frequency (intraday or daily) data. In the Appendix we show that measurement errors in transaction prices bias the nontrading and trading variance ratios, $V_{1}$ and $V_{2}$ in (3), toward 0.50 . This bias, in turn, leads to problems in drawing inferences from variance ratios of individual securities. First, it is difficult to determine either the direction or the magnitudes of the biases for different ratios, because the biases depend not only on the degree of measurement error in transaction prices but also on the

\footnotetext{
${ }^{4}$ We use the regression in (2) to calculate the nontrading and trading variances largely for convenience. Note that we have to use a regression to calculate the 'mean' returns because we condition on different days of the week in (1) and, in Section 2.5, we condition on lagged returns to adjust for stickiness in quotes in (4). Since nontrading and trading days are ex ante unpredictable, in estimating expected returns in (1), or in (4), we do not distinguish between these days. Consequenlly, it is convenient to also use a regression to calculate variances [see (2)] because, except for the nonconditioning of mean returns on nontrading and trading days, the regression approach in (2) is identical to calculating the nontrading and trading variances directly.
} 
unobservable true variance ratios. Therefore, both the direction and the magnitudes of the biases are likely to be different for different variance ratios. Second, and more importantly, the biases will tend to camouflage any systematic cross-sectional or time-series patterns in the true variance ratios.

One possible way to eliminate the noise in transaction returns induced by bid/ask errors is to calculate returns based on the average of closing bid and ask quotes for both nontrading and trading days. ${ }^{5}$ These quotes are available for only NASDAQ-NMS securities. To provide some idea of the extent of the potential bias due to bid/ask errors, we calculate all variance ratios based on both transaction returns and quote returns. Note that transaction returns are particularly problematic in the context of our study because CRSP's transaction price is a noisy measure of a security's value on a trading day, but measures value without any bid/ask bounce on a nontrading day (since CRSP reports the average of bid and ask quotes as the transaction price on nontrading days).

The use of quote returns would seem to eliminate this problem. However, quote-return-based variance ratios may themselves be biased. (We thank the referee, Ken French, for pointing out the potential problems associated with the use of quote returns for NASDAQ firms.) In a recent investigation of the quote-setting behavior of NASDAQ dealers, Geraghty (1992) finds that there are a large number of NASDAQ-NMS stocks whose bid and ask quotes remain unaltered from one day to the next, even if they experience trading. On average, over $50 \%$ of the securities on the NASDAQ have end-of-day inside market quotes unchanged from the previous day, and this proportion is about twice as large for the smallest-quintile versus largest-quintile firms. The stickiness in the quotes, in turn, leads to positive serial correlation in the quote returns of virtually all NASDAQ securities (see also Kaul and Nimalendran, 1990).

If the stickiness in quotes is at least partly due to delayed adjustments by the market maker to marketwide or firm-specific information (see Jones, 1993), we need to correct for it. Consequently, we calculate an alternative set of variance ratios using quote returns conditioned not only on day-of-the-week dummies [see (1)], but also on five lagged own returns and the contemporaneous and five lagged returns on the market portfolio. Specifically, we estimate an altered form of (1):

$$
R_{i t}=\sum_{k=1}^{5} \alpha_{i k} D_{k t}+\sum_{l=1}^{5} \theta_{i l} R_{i(t-l)}+\sum_{h=0}^{5} \beta_{i h} R_{m(l-h)}+\varepsilon_{i l},
$$

\footnotetext{
${ }^{5}$ We assume that the true price of a stock changes over time only due to the arrival of new (public or private) information. Based on the findings of Kaul and Nimalendran (1990), we assume that irrational noise-trading or market overreaction does not generate any spurious volatility in shorthorizon returns of NASDAQ-NMS firms. Also, the bid/ask bounce is presumed to be the major source of measurement error(s) in transaction prices (see Blume and Stambaugh, 1983; Kaul and Nimalendran, 1990)
} 
where $R_{m t}$ is the return on the value-weighted index of NYSE/AMEX stocks.

Five lagged returns are chosen to coincide with a week's worth of returns. To avoid data dredging we restrict ourselves to the lag specification in (4). Apart from capturing any lagged adjustments in quotes due to market effects, the contemporaneous and lagged market returns have the additional advantage of capturing the potential consequences of private information revealed through trades in one stock for other (possibly nontraded) stocks in the sample. We use the squared residuals obtained from estimates of (4) for individual securities to calculate the variance ratios defined in (3).

Finally, since the sampling distributions of the variance ratios are highly asymmetric, we report the medians of the variance ratios of individual securities because they are more likely to represent the ratio of the typical firm in the cross-sectional samples. The medians are corrected for two problems inherently associated with variance ratios. First, in this paper, as in all previous papers studying exchange closings, the number of observations in the numerators of the variance ratios is less than the number in the denominators. This leads to a downward bias in the median, particularly for cases in which the number of observations in the numerator are small in absolute magnitude (see Merrington and Thompson, 1943). Second, because high-frequency returns are not normally distributed (see Fama, 1965), the variance ratios do not have an $F$-distribution. Consequently, it is difficult to analytically determine the extent of the downward bias in the medians of the variance ratios. We therefore use a bootstrap procedure to correct for the downward bias in the median estimates. The standard deviations of the medians are also calculated using a similar procedure. (Brief descriptions of the bootstrap procedures used to estimate the bias in the median estimators and to calculate their standard deviations are presented in the Appendix.)

\section{Trading and volatility}

In Table 3 we report the (bias-adjusted) median estimates of nontrading to trading variance ratios (that is, the ratios of variances on nontrading and trading days when business and exchanges are open). We report the ratios for both weekends (that is, Mondays) and weekdays. Panel A contains median ratios based on returns calculated using the average of the bid and ask prices, $R^{a}$, and panel B shows median ratios computed from transaction returns, $R^{t}$. The numbers in parentheses below the medians are their (bias-adjusted) standard errors obtained from a bootstrap procedure (see the Appendix). The (bootstrap) sampling distributions of the median statistics closely approximate normality, which is not surprising because the distribution of the sample median is approximately normal in large samples (see DeGroot, 1989). Consequently, the (biasadjusted) standard deviations of the sampling distributions can be used as 
Table 3

Median ratios of nontrading to trading volatilities for NASDAQ-NMS stocks, 1984-1991

The estimates are based on daily returns calculated using the average of closing bid and ask prices, $R^{a}$ (panel $\mathrm{A}$ ), and transaction prices, $R^{i}$ (panel $\mathrm{B}$ ), for securities belonging to five portfolios formed by rankings of market value of equity outstanding at the beginning of each six-month (126-trading-day) period. All statistics are estimated for every firm that has at least one trading day and one nontrading day for both Mondays and the Tuesday -Friday interval during a subperiod. We first estimate the following regression for each security in each subperiod:

$\hat{\varepsilon}_{i t}^{2}=\sigma_{i N T M}^{2} D_{N T M t}+\sigma_{i T M}^{2} D_{T M t}+\sigma_{i N T T F}^{2} D_{N T T F t}+\sigma_{i T T F}^{2} D_{T T F t}+\sigma_{i D H}^{2} D_{1 D H t}+\sigma_{i 3 D H}^{2} D_{3 D H t}+v_{i t}$, where $\hat{\varepsilon}_{i t}^{2}$ is the squared residual of the return of security $i$ in period $t$ conditional on day-of-the-week dummies, the dummy variable coefficients $\sigma_{i N T M}^{2}$ and $\sigma_{i T M}^{2}$ measure the intercepts for nontrading and trading Mondays, the coefficients $\sigma_{i N T T F}^{2}$ and $\sigma_{i T T F}^{2}$ measure the intercepts when there is nontrading and trading on a particular day during the Tuesday-Friday interval, and $\sigma_{i I D H}^{2}$ and $\sigma_{i 3 D H}^{2}$ measure the intercepts for a one-day and a three-day (long-weekend) holiday. The nontrading to trading volatility ratios on weekends and weekdays are calculated as $\sigma_{\text {INTM }}^{2} / \sigma_{\text {iTM }}^{2}$ and $\sigma_{\text {INTTF }}^{2} / \sigma_{\text {iTTF }}^{2}$, respectively. We report the median estimate for each portfolio of the distribution of the individualfirm variance ratios over the entire 1984-1991 sample period. Median estimates of the two variance ratios are corrected for small-sample biases using a bootstrap procedure (see the Appendix). The numbers in parentheses are the standard errors of the median statistics ohtained from the bootstrap procedure. The second column reports the total number of observations for each portfolio over all subperiods used to calculate the median variance ratios.

\begin{tabular}{llll}
$\begin{array}{l}\text { No. of } \\
\text { observations }\end{array}$ & $\begin{array}{l}\text { Weekend } \\
\text { ratio }\end{array}$ & $\begin{array}{l}\text { Weekday } \\
\text { ratio }\end{array}$ \\
\hline
\end{tabular}

Panel $A$ : Using returns based on average of bid and ask prices, $R^{a}$

$\begin{array}{lccc}1 \text { (smallest) } & 4505 & 0.094 & 0.115 \\ 2 & & (0.005) & (0.002) \\ & 3430 & 0.116 & 0.114 \\ 3 & & (0.008) & (0.003) \\ & 2479 & 0.130 & 0.112 \\ 4 & 1757 & (0.009) & (0.004) \\ & & 0.132 & 0.123 \\ 5 \text { (largest) } & 707 & (0.013) & (0.005) \\ & & 0.161 & 0.136 \\ & & (0.020) & (0.007)\end{array}$

Panel B: Using returns based on transaction prices, $R^{t}$

$\begin{array}{lccc}1 \text { (smallest) } & 4505 & 0.405 & 0.404 \\ 2 & & (0.008) & (0.004) \\ & 3430 & 0.439 & 0.421 \\ 3 & 2479 & (0.010) & (0.005) \\ & & 0.431 & 0.421 \\ 4 & 1757 & (0.012) & (0.006) \\ & & 0.449 & 0.413 \\ 5 \text { (largest) } & 707 & (0.016) & (0.007) \\ & & 0.485 & 0.435 \\ & & (0.025) & (0.012)\end{array}$


standard errors to conduct hypotheses tests. We also use the entire simulated sampling distributions of the medians (and calculate $p$-values) to confirm the validity of inferences based on the standard errors. Column 2 reports the total number of firm-observations over all subperiods used to estimate the median variance ratios for each portfolio.

Both the weekend and weekday nontrading to trading variance ratios directly measure the relative importance of trading in the movement of stock prices. The estimates in panel A show that nontrivial proportions of price movements occur even in the absence of trading. However, the most interesting aspect of the evidence is that there is a systematic positive relation between the variance ratios and firm size. The weekend ratios increase from about $9 \%$ for the smallest firms to $16 \%$ for the largest firms, and the corresponding numbers for the weekday ratios are $12 \%$ and $14 \%$. The medians of the largest firms (portfolio 5) are statistically significantly greater than those of the smallest firms (portfolio 1).

The estimates in panel $B$ show the dramatic effects of bid/ask bounce in transaction prices on the variance ratios, and how these effects can result in misleading inferences. There is a substantial (upward) bias toward 0.50 in both the weekend and weekday estimates, with the median ratios varying between 0.40 and 0.49 . The upward bias in these ratios occurs because the estimates in panel $\mathrm{A}$ are all less than 0.50 , and the bias is proportionately much greater for the small firms. Therefore, the conventional use of transaction prices tends to camouflage any cross-sectional (or time-series) patterns in the true variance ratios. In the context of this paper, we see that the positive relation between firm size and the nontrading and trading variance ratios that is quite apparent in panel $\mathrm{A}$ is considerably attenuated in panel $\mathrm{B}$. Also, measurement errors in transaction prices lead to the potentially erroneous conclusion that close to $50 \%$ of return volatility of all firms occurs without any trades.

\subsection{Variance ratios based on adjusted quote returns}

Table 3 shows that nontrading and trading variance ratios based on transaction returns appear to be implausibly large. However, the variance ratios based on quote returns in panel A could also be biased due to stickiness in the daily quotes of NASDAQ-NMS firms. We therefore present and analyze an alternative set of nontrading and trading variance ratios based on quote returns adjusted for lagged own and market effects [see eq.(4)]. Table 4 contains median estimates of these variance ratios for all portfolios, with standard errors in parentheses.

The most significant difference between the estimates based on the unadjusted and adjusted quote returns (see Table 3, panel A, as well as Table 4) is that the ratios are typically two to three times larger in Table 4 . The nontrading to trading ratios for weekends range between $22 \%$ and $30 \%$ in Table 4 compared to values between $9 \%$ and $16 \%$ based on unadjusted quote returns in Table 3 , 
Table 4

Median ratios of nontrading to trading volatilities using returns of NASDAQ-NMS stocks based on averages of closing bid and ask prices conditional on lagged own and market returns, 1984-1991

The estimates are based on daily returns calculated using the average of closing bid and ask prices, $R^{a}$, for securities belonging to five portfolios formed by rankings of market value of equity outstanding at the beginning of each six-month (126-trading-day) period. All statistics are estimated for every firm that has at least one trading day and one nontrading day for both Mondays and the Tuesday-Friday interval during a subperiod. We first estimate the following regression for each security in each subperiod:

$\hat{\varepsilon}_{i t}^{2}=\sigma_{i N T M}^{2} D_{N T M t}+\sigma_{i T M}^{2} D_{T M t}+\sigma_{i N T T H}^{2} D_{N T T F t}+\sigma_{i T T F}^{2} D_{T T F t}+\sigma_{i D H}^{2} D_{1 D H t}+\sigma_{i 3 D H}^{2} D_{3 D H}+v_{i t}$,

where $\hat{\varepsilon}_{i t}^{2}$ is the squared residual of the return of security $i$ in period $t$ conditional on day-of-the-week dummies, five lagged own returns, and the contemporaneous and five lagged returns on the value-weighted index of NYSE/AMEX stocks; the dummy variable coefficients $\sigma_{i N T M}^{2}$ and $\sigma_{i T M}^{2}$ measure the intercepts for Mondays when there is nontrading and trading, the coefficients $\sigma_{i N T T F}^{2}$ and $\sigma_{i T T F}^{2}$ measure the intercepts when there is nontrading and trading on a particular day during the Tuesday-Friday interval, and $\sigma_{i 1 D H}^{2}$ and $\sigma_{i 3 D H}^{2}$ measure the intercepts for a one-day and a three-day (long-weekend) holiday. The nontrading and trading volatility ratios on weekends and weekdays are calculated as $\sigma_{i N T M}^{2} / \sigma_{i T M}^{2}$ and $\sigma_{i N T T F}^{2} / \sigma_{i T T F}^{2}$, respectively. We report the median estimate for each portfolio of the distribution of the individual-firm variance ratios over the entire 1984-1991 sample period. Median estimates of the two variance ratios are corrected for smallsample biases using a bootstrap procedure (see the Appendix). The numbers in parentheses are the standard errors of the median statistics obtained from the bootstrap procedure. The second column reports the total number of observations for each portfolio over all subperiods used to calculate the median variance ratios.

\begin{tabular}{|c|c|c|c|}
\hline Portfolio & $\begin{array}{l}\text { No. of } \\
\text { observations }\end{array}$ & $\begin{array}{l}\text { Weekend } \\
\text { ratio }\end{array}$ & $\begin{array}{l}\text { Weekday } \\
\text { ratio }\end{array}$ \\
\hline 1 (smallest) & 4505 & $\begin{array}{c}0.220 \\
(0.007)\end{array}$ & $\begin{array}{c}0.191 \\
(0.003)\end{array}$ \\
\hline 2 & 3430 & $\begin{array}{c}0.265 \\
(0.010)\end{array}$ & $\begin{array}{c}0.214 \\
(0.004)\end{array}$ \\
\hline 3 & 2479 & $\begin{array}{c}0.263 \\
(0.012)\end{array}$ & $\begin{array}{c}0.237 \\
(0.005)\end{array}$ \\
\hline 4 & 1757 & $\begin{array}{c}0.282 \\
(0.017)\end{array}$ & $\begin{array}{c}0.248 \\
(0.007)\end{array}$ \\
\hline 5 (largest) & 707 & $\begin{array}{c}0.303 \\
(0.028)\end{array}$ & $\begin{array}{c}0.290 \\
(0.012)\end{array}$ \\
\hline
\end{tabular}

panel A. Similarly, the weekday ratios in Table 4 range between $19 \%$ and $29 \%$ compared to corresponding values of $12 \%$ to $14 \%$ in Table 3, panel A. Also, the variance ratios in Table 4 continue to show a systematic positive relation with size. In fact, this relation is even more pronounced than in Table 3; for both weekends and weekdays the ratios for the largest firms in portfolio 5 are about $50 \%$ larger than the ratios for the smallest firms in portfolio 1. 


\subsection{Subperiod evidence}

In this section, we present evidence on the behavior of the nontrading to trading variance ratios over time. For brevity we present details only for the overall sample and not for each portfolio. Figs. 1A and $1 \mathrm{~B}$ plot the subperiod

\section{A. Weekend nontrading/trading}

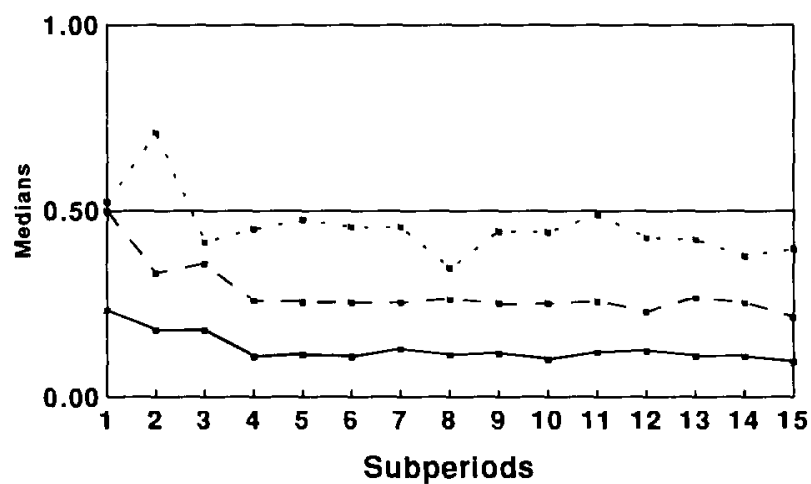

$\rightarrow$ Bid-ask $\cdots$ Transaction $\rightarrow$ Adjusted B/A

B. Weekday nontrading/trading

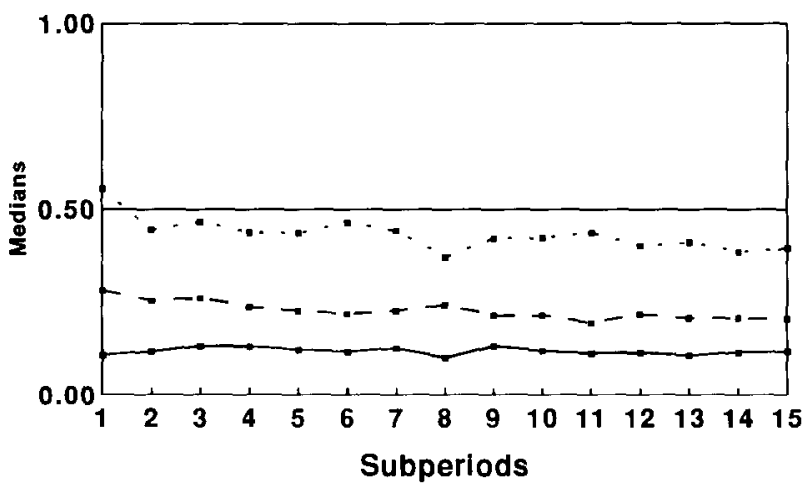

Bid-ask - - Transaction - Adjusted B/A

Fig. 1. Bias-adjusted subperiod medians of variance ratios for all firms calculated using returns based on transaction prices and returns based on the average of closing bid and ask prices. Returns are conditioned on day-of-week dummies only, except for adjusted bid/ask ratios, which are calculated using returns conditioned on five past own returns, five past market returns, and the current market return. 
bias-adjusted medians for the weekend and weekday nontrading to trading ratios, respectively. Each figure contains the bias-adjusted subperiod medians calculated from transaction returns (dotted lines), unadjusted quote returns (solid lines), and adjusted quote returns (dashed lines). Subperiod 8 contains the 1987 stock market crash.

The salient time-series feature of the subperiod weekend and weekday nontrading to trading ratios is their remarkable stability, regardless of the returns used to calculate the ratios. The stability of the medians computed from transaction returns is not surprising because they are consistently (upward) biased toward 0.50 . However, except for differences in levels, even the ratios based on unadjusted and adjusted quote returns are stable through time. Note that the median estimates of the variance ratios may be relatively unreliable for the first three subperiods because there are less than 200 observations in each of these subperiods, while all other subperiods have between 600 and 1300 observations. (The subperiod-1 medians may be particularly unreliable because they are based on only 68 observations.)

Perhaps the most interesting aspect of the stability of the nontrading to trading median ratios is that they do not even change during the $1987 \mathrm{crash}$ subperiod. For example, the crash medians for the weekend and weekday ratios based on unadjusted quote returns are 0.111 and 0.100 , with the corresponding noncrash medians being 0.115 and 0.117 . The behavior of the crash median ratios is interesting because the average level of daily volatility during this subperiod was about two to three times higher than during the noncrash periods, depending on the size of the firm and the day of the week under consideration. Since the ratios of nontrading to trading volatilities remained the same during the crash subperiod, a substantial amount of volatility occurred without trade during this subperiod.

The nontrading to trading variance ratios in Tables 3 and 4 are direct measures of the relation between trading and volatility and demonstrate that a substantial degree of volatility occurs without trading. Furthermore, the proportion of price movements that occur without trade is positively related to firm size. Given that large firms are widely followed by market participants, this evidence suggests that it may be easier for agents to concur on the implications of certain public events for large firms.

\section{Information flows and volatility}

We use our nontrading and trading classifications to gauge the relative importance of public versus private information. We consider two alternative assumptions about the flows of public and private information and their influence on trading. First, we follow previous researchers (see, for example, French and Roll, 1986; and Hasbrouck, 1991) and assume that public information is 
produced at a constant rate on days when exchanges and businesses are open and that it affects prices without trade. The arrival of private information, on the other hand, is stochastic and trading is necessary for such information to affect prices. Under these conditions, the nontrading to trading variance ratios are measures of the relative importance of public information, and therefore our results in Section 3 suggest that although public information is a significant determinant of volatility, private information still plays a primary role. Alternatively, we assume that private information is a small (or economically negligible) fraction of all information and that public information induces trading. Under this scenario, the nontrading to trading variance ratios in Tables 3 and 4 appear to document wide fluctuations in the flow of public information.

Clearly, these two scenarios are simple polar representations of potentially complex flows of information and intricate interactions between information and trading decisions. Furthermore, though our tests in this section provide evidence on which of the above scenarios more closely describes observed volatility, they do not rule out other explanations. Nevertheless, we use these two cases as benchmarks for assessing the relation between information flows and volatility.

\subsection{Importance of private information}

We first estimate the adverse-selection components of bid/ask spreads of securities in our sample to measure the relative importance of private information. To test the predictions of strategic models of trading that the adverseselection component will reflect patterns when markets are closed (such as weekends), we estimate the adverse-selection component for each day of the week. ${ }^{6}$ We calculate the adverse-selection component of the bid/ask spread using the procedure in George, Kaul, and Nimalendran (1991). Specifically, the adverse-selection component for security $i$ on the $j$ th day of the week, $\theta_{i j}$, is given by

$$
\theta_{i j}=s_{i j}-2 \sqrt{-\operatorname{cov}\left(R D_{i j t}, R D_{i j(t-1)}\right)},
$$

where $s_{i j}$ is the average quoted spread in percent for security $i$ on day $j$ of the week, $j=1, \ldots, 5$, and $R D_{i j t}$ is the difference between the weekly transaction and bid returns for day $j$ in week $t$.

\footnotetext{
${ }^{6}$ Strategic models of trading show that private information could accumulate at the same rate during market closures as on a regular trading day, and yet weekend-to-weekday variance ratios could be substantially lower than 3.0 as found by French and Roll (1986) (see also Section 4.3). This could occur if discretionary liquidity traders postpone their trades from Monday to the rest of the week due to the relatively acute asymmetry of information on Mondays. Under these circumstances, trading costs (in particular, the adverse-selection component of spreads) will be the highest on Mondays (see Foster and Viswanathan, 1990, 1993a; and also Kyle, 1985; Admati and Pfleiderer, 1988).
} 
To gauge the relative importance of private information, we estimate the size of the adverse-selection component relative to the total quoted spread, that is,

$$
a_{i j}=\frac{\theta_{i j}}{s_{i j}} \quad \text { where } \quad 0 \leqslant a_{i j} \leqslant 1.0 .
$$

The statistic $a_{i j}$ is a measure of the extent of private information in securities markets (and therefore the extent of information asymmetry). Note that if private information is the sole determinant of spreads, then $a_{i j}$ equals one. On the other hand, if there is no private information in the market, $a_{i j}$ equals zero. The extent of information asymmetry duc to private information can therefore be measured by the relative magnitude of $a_{i j}$. Finally, since $a_{i j}$ is a unitless measure, it can be used to compare the extent of private information of large versus small securities (see Glosten and Milgrom, 1985; Glosten, 1987; George, Kaul, and Nimalendran, 1991).

Since the estimation of $\theta_{i j}$ requires transaction prices and bid/ask quotes, we estimate both $\theta_{i j}$ 's and $a_{i j}$ 's for all NASDAQ-NMS securities that trade every day during a six-month subperiod. Consequently, the sample of securities is different from the one used to estimate the variance ratios reported in previous Tables. However, we categorize firms into five market-value portfolios using the same cutoffs as for the original sample. Any patterns found in the portfolio $\hat{a}_{i j}$ 's should therefore reflect the general patterns for securities in the corresponding market-value portfolios. As it turns out, this sample selection procedure probably has no effect on our inferences because the $\hat{a}_{i j}$ 's are constant across securities of different market value.

Estimates of levels of the relative size of the adverse-selection component of spreads, in percent, are reported in Table 5. All estimates are averages of individual security estimates over all subperiods, with standard errors in parentheses. In calculating both $\theta_{i j}$ 's and $a_{i j}$ 's, we delete observations for which $\operatorname{cov}\left(R D_{i j t}, R D_{i j t-1}\right)$ is positive, and we set them equal to zero if its estimated value is negative. The standard errors are calculated under the assumption that the individual-firm parameters are independent and identically distributed within a particular portfolio. Since the parameters are likely to have positive cross-sectional correlation these standard errors are biased downward.

The most important evidence in Table 5 is that the adverse-selection component is a small proportion (between $12 \%$ and $15 \%$ ) of quoted spreads, regardless of the market values of the securities. On average, there appears to be relatively little private information in securities markets. The surprising aspect of the estimates in Table 5 is that the $\hat{a}_{i j}$ 's are constant across large and small firms. Therefore, not only does private information play a small role in asset markets, but the relative importance of such information appears to be no higher for small than for large firms (see also George, Kaul, and Nimalendran, 1991).

Finally, the extent of adverse selection is unchanged following market closures. The $F$-statistics cannot reject the equality of the adverse-selection components 
Table 5

Relative size of the adverse-selection component by day-of-the-week for NASDAQ-NMS stocks, $1984-1991$

This table contains average estimates for each day of the week of the relative size (in percent) of the adverse-selection component of the bid/ask spread. The estimates are calculated for every firm that trades each day during a 126-trading-day subperiod. We report the averages of individual-firm statistics across all subperiods for securities belonging to five portfolios formed by rankings of market value of equity outstanding at the beginning of each six-month (126-trading-day) subperiod.

The adverse-selection component is calculated as $\theta_{i}=s_{i}-2 \sqrt{-\operatorname{cov}\left(R D_{i t}, R D_{i t-1}\right)}$, where $s_{i}$ is the quoted spread calculated as $\left(P_{A}-P_{B}\right) / \frac{1}{2}\left(P_{A}+P_{B}\right)$, where $P_{A}$ and $P_{B}$ are the daily closing ask and bid prices of security $i, R D_{i t}$ is the difference between returns based on transaction prices and returns calculated using bid prices, and $\operatorname{cov}\left(R D_{i t}, R D_{i t-1}\right)$ for a particular day of the week is calculated using returns ending on that day of the week only (that is, using weekly returns ending on the weekday under consideration). We report average estimates of the relative size (in percent) of the adverseselection component, i.e., $a_{i}=\theta_{i} / s_{i}$ for all days of the week. The numbers in parentheses below the averages are their standard errors under the assumption that the individual-firm parameters are independent and identically distributed. In the last column we report $F$-statistics (with $p$-values in brackets) to test the hypothesis that the adverse-selection components are equal across all days of the week. The second column reports the total number of observations for each portfolio over all subperiods used to calculate the repotted averages.

\begin{tabular}{lllllllc}
\hline Portfolio & $\begin{array}{l}\text { No. of } \\
\text { observations }\end{array}$ & Monday & Tuesday & Wednesday & Thursday & Friday & $\begin{array}{c}F \\
{[p \text {-value }]}\end{array}$ \\
\hline 1 (smallest) & 385 & 14.80 & 14.49 & 14.06 & 12.66 & 15.23 & 1.306 \\
2 & & $(1.00)$ & $(0.95)$ & $(0.89)$ & $(0.86)$ & $(0.95)$ & {$[0.226]$} \\
& \multirow{2}{*}{1009} & 14.03 & 13.64 & 13.96 & 15.00 & 14.04 & 0.883 \\
3 & & $(0.58)$ & $(0.54)$ & $(0.53)$ & $(0.57)$ & $(0.54)$ & {$[0.473]$} \\
& \multirow{2}{*}{1808} & 15.47 & 15.17 & 14.97 & 14.99 & 14.71 & 0.474 \\
4 & & $(0.42)$ & $(0.43)$ & $(0.41)$ & $(0.41)$ & $(0.42)$ & {$[0.755]$} \\
& 2626 & 14.79 & 14.34 & 14.64 & 14.92 & 14.24 & 0.757 \\
5 (largest) & 3977 & $(0.35)$ & $(0.33)$ & $(0.33)$ & $(0.34)$ & $(0.34)$ & {$[0.553]$} \\
& & 14.66 & 13.55 & 15.16 & 14.81 & 14.09 & 5.528 \\
& & $(0.28)$ & $(0.26)$ & $(0.28)$ & $(0.28)$ & $(0.27)$ & {$[0.000]$} \\
\hline
\end{tabular}

on different days of the week for portfolios 1-4 (see last column, Table 5); the $p$-values range between 0.27 and 0.76 . Consistent with the evidence in Foster and Viswanathan (1993a), for the large firms in portfolio 5 there is statistically significant variation in the adverse-selection component. The economic significance of this variation, however, appears to be questionable because the point estimate of Monday's adverse-selection component is only marginally higher than Tuesday's and is actually lower than both Wednesday's and Thursday's estimates. Consequently, the evidence in Table 5 provides little support for asymmetric information models which suggest that (relative to a normal day) there is an excess accumulation of private information when markets are closed. Moreover, none of the portfolios show any systematic variation over different days of the week in the levels of the quoted spreads. 


\subsection{Market microstructure effects on nontrading and trading days}

The preceding analysis suggests that since the adverse-selection component of quoted spreads is small for all securities, private information on average may not be a major source of short-run price changes. However, the adverse-selection and quoted bid/ask spreads in Table 5 are unconditional estimates; they do not distinguish between trading and nontrading periods. If public information is the sole determinant of short-run volatility and, therefore, the substantially higher variances on trading days are due to a higher flow of such information, the adverse-selection component of bid/ask spreads should be close to zero for both trading and nontrading days. Conversely, if trading is due solely to private information, the adverse-selection component during trading days would be greater than during nontrading days. ${ }^{7}$ Consequently, a comparison of the adverse-selection components of spreads on nontrading and trading days should help us distinguish between our two stylized representations of the relation between information flows and trading.

Recall, however, that we require closing quotes and transaction prices (particularly the latter) to calculate the adverse-selection component of the spreads (see Glosten, 1987; Stoll, 1989; George, Kaul, and Nimalendran, 1991). Since only closing quotes are available on nontrading days, we cannot calculate the adverse-selection component for these days. However, since order-processing costs are likely to be constant across different days, and there is virtually no extant evidence of inventory-holding costs (see Stoll, 1989; George, Kaul, and Nimalendran, 1991), differences in the quoted spreads themselves should indicate differences in the adverse-selection component. Thus, if trading days are associated with an increase in the flow of private information and, therefore, an increase in adverse selection, the quoted spreads should be higher on trading days than on nontrading days.

Average estimates of the quoted spreads on nontrading and trading days are reported in Table 6 . Since we do not require transaction prices and quotes to be available each day, the sample used to calculate the spreads is identical to the one used to estimate the nontrading to trading variance ratios in Tables 3 and 4. The numbers in parentheses below the average estimates are their standard errors calculated under the assumption that individual-security quoted spreads are independent and identically distributed within a particular portfolio. The last column contains $t$-tests (with $p$-values in parentheses) of the hypothesis that the bid/ask spreads are equal on nontrading and trading days.

\footnotetext{
${ }^{7}$ In a recent paper, Easley and O'Hara (1992) explicitly model the effects of time on stock prices and spreads in a world with asymmetric information. They show that the absence of trade during a particular period will lead to a lowering of the spread by the market-maker. This occurs because the absence of trade is also informative (to the market-maker) in that it is more likely to occur when no (private) information event has occurred.
} 
Table 6

Relative bid/ask spreads on nontrading and trading days for NASDA Q-NMS stocks, 1984-1991

This table contains average estimates of the quoted bid/ask spreads on nontrading and trading days. The estimates are based on daily spreads for securities belonging to five portfolios formed by rankings of market value of equity outstanding at the beginning of each six-month (126-trading-day) period. The spreads are calculated for every firm that has at least one trading day and one nontrading day for both Mondays and the Tyesday-Friday interval during a subperiod. The quoted spread of a firm, $s_{i}$, is calculated as $\left(P_{A}-P_{B}\right) / \frac{1}{2}\left(P_{A}+P_{B}\right)$, where $P_{A}$ and $P_{B}$ are the daily closing ask and bid prices of firm $i$. The numbers in parentheses below the averages are their standard errors under the assumption that the individual-firm parameters are independent and identically distributed. In the last column we report $t$-statistics (with $p$-values in brackets) to test the hypothesis that the average bid/ask spreads are equal on nontrading and trading days. The second column reports the total number of observations for each portfolio over all subperiods used to calculate the reported averages.

\begin{tabular}{|c|c|c|c|c|}
\hline Portfolio & $\begin{array}{l}\text { No. of } \\
\text { observations }\end{array}$ & Nontrading & Trading & ${ }^{t}[p$-value $]$ \\
\hline 1 (smallest) & 4505 & $\begin{array}{l}12.875 \\
(0.127)\end{array}$ & $\begin{array}{l}12.332 \\
(0.125)\end{array}$ & $\begin{array}{c}0.543 \\
{[0.0001]}\end{array}$ \\
\hline 2 & 3430 & $\begin{array}{c}7.976 \\
(0.077)\end{array}$ & $\begin{array}{c}7.534 \\
(0.073)\end{array}$ & $\begin{array}{c}0.442 \\
{[0.0001]}\end{array}$ \\
\hline 3 & 2479 & $\begin{array}{c}6.136 \\
(0.069)\end{array}$ & $\begin{array}{c}5.749 \\
(0.064)\end{array}$ & $\begin{array}{c}0.387 \\
{[0.0001]}\end{array}$ \\
\hline 4 & 1757 & $\begin{array}{c}4.582 \\
(0.060)\end{array}$ & $\begin{array}{c}4.342 \\
(0.055)\end{array}$ & $\begin{array}{c}0.240 \\
{[0.0001]}\end{array}$ \\
\hline 5 (largest) & 707 & $\begin{array}{c}3.623 \\
(0.085)\end{array}$ & $\begin{array}{c}3.439 \\
(0.081)\end{array}$ & $\begin{array}{c}0.184 \\
{[0.0001]}\end{array}$ \\
\hline
\end{tabular}

The evidence in Table 6 shows that although quoted spreads are actually consistently lower on trading days, the differences in spreads are economically trivial for securities belonging to all portfolios. Specifically, the differences are only $4 \%$ to $6 \%$ of the quoted spreads on trading days. We arrive at similar conclusions if we calculate the means (or medians) of the ratios of spreads on nontrading and trading days. This evidence again appears to be consistent with the hypothesis that private information plays a small role in asset markets; changing flows of public information appear to be the main source of differences in volatility on trading and nontrading days.

\subsection{The effects of exchange closings on volatility}

We conduct a final set of tests to gauge the relative importance of private versus public information. We use our nontrading and trading classification to compare the relative weekend-to-weekday nontrading volatilities with the 
relative weekend-to-weekday trading volatilities. Specifically, we use the estimates of (2) to calculate the following variance ratios:

$$
V_{3}=\frac{\sigma_{i N T M}^{2}}{\sigma_{i N T T F}^{2}} \quad \text { and } \quad V_{4}=\frac{\sigma_{i T M}^{2}}{\sigma_{i T T F}^{2}}
$$

These ratios are similar to weekend-to-weekday variance ratios calculated by earlier researchers (see, for example, French and Roll, 1986), except that we compute separate ratios based on our definition of nontrading. Thus, ratio $V_{3}$ compares the variance of returns from Friday to Monday when no trades occur on Monday to the average variance of returns on a weekday when no trade occurs on the weekday. Ratio $V_{4}$ is the same weekend-to-weekday variance ratio when trades do occur on both the Mondays and the weekdays.

Consider the conditions necessary for ratios $V_{3}$ and $V_{4}$ to be equal. If $V_{3}$ reflects only the flow of public information and $V_{4}$ reflects the flow of both public and private information, these two ratios can be equal only if (a) public information is the primary determinant of volatility or $(b)$ private information gathering over a weekend is reduced by exactly the reduction in the flow of public information over a weekend. We find that the ratios are, in fact, equal and, given the implausibility of the second condition, our interpretation of this evidence is that private information is a small fraction of the total flow of information.

Our test of this hypothesis is shown in Table 7, which presents the biasadjusted median estimates of the weekend nontrading and trading variance ratios based on adjusted quotes. For brevity, we only report variance ratios based on adjusted quotes because ratios based on transaction prices are biased toward one and unadjusted quotes are sticky. The numbers in parentheses below the median estimates are their (bias-adjusted) standard errors.

Table 7 demonstrates that within each market-value portfolio the weekendto-weekday nontrading and trading variance ratios are similar. We also conduct a formal test of the hypothesis that the median weekend nontrading and trading variance ratios, $V_{3}$ and $V_{4}$, are identical for securities in each portfolio using a bootstrap procedure described in the Appendix. These tests typically cannot reject the hypothesis that $V_{3}$ and $V_{4}$ are equal, regardless of the market valucs of the securities: the $p$-values of the test statistics are consistently greater than $1 \%$, and only the median ratios for portfolio 2 are different at the $5 \%$ significance level.

Taken together, the evidence presented in Tables 5-7 suggests that private information contributes little to observed volatility. However, we have only considered two simple characterizations of the relation between information flows and trading, and other, more complex, hypotheses could be consistent with our results. 
Table 7

Median ratios of weekend-to-weekday volatilities using return of NASDAQ-NMS stocks based on average of closing bid and ask prices conditioned on lagged own and market returns, 1984-1991

The estimates are based on daily returns calculated using the average of closing bid and aks prices, $R^{a}$, for securities belonging to five portfolios formed by rankings of market value of equity outstanding at the beginning of each six-month (126-trading-day) period. All statistics are estimated for every firm that has at least one trading day and one nontrading day for both Mondays and the Tuesday-Friday interval during a subperiod. We first estimatc the following regression for each security in each subperiod:

$\hat{\varepsilon}_{i t}^{2}=\sigma_{i N T M}^{2} D_{N T M t}+\sigma_{i T M}^{2} D_{T M t}+\sigma_{i N T T F}^{2} D_{N T T F t}+\sigma_{i T T F}^{2} D_{T T F t}+\sigma_{i I D H}^{2} D_{I D H t}+\sigma_{i 3 D H}^{2} D_{3 D H t}+v_{i t}$,

where $\hat{\varepsilon}_{i t}^{2}$ is the squared residual of the return of security $i$ in period $t$ conditional on day-of-the-week dummies, five lagged own returns, and the contemporaneous and five lagged returns on the value-weighted index of NYSE/AMEX stocks; the dummy variable coefficients $\sigma_{\text {iNTM }}^{2}$ and $\sigma_{i T M}^{2}$ measure the intercepts for Mondays when there is nontrading and trading, the coefficients $\sigma_{\text {iNTTF }}^{2}$ and $\sigma_{\text {iTTF }}^{2}$ measure the intercepts when there is nontrading and trading on a particular day during the Tuesday-Friday interval, and $\sigma_{i I D H}^{2}$ and $\sigma_{i, B D H}^{2}$ measure the intercepts for a one-day and a three-day (long-weekend) holiday. The nontrading and trading volatility ratios on weekends and weekdays are calculated as $\sigma_{i N T M}^{2} / \sigma_{i T M}^{2}$ and $\sigma_{i N T T F}^{2} / \sigma_{\text {TTTF }}^{2}$. We report the median estimate of the distribution of the individual-firm variance ratios over the entire 1984-1991 sample period. Median estimates of the two variance ratios are corrected for small-sample hiases using a hootstrap procedure (see the Appendix). The numbers in parentheses are the standard errors of the median statistics obtained from the bootstrap procedure. The second column reports the total number of observations for each portfolio over all subperiods used to calculate the median variance ratios.

\begin{tabular}{lccc} 
Portfolio & $\begin{array}{l}\text { No. of } \\
\text { observations }\end{array}$ & $\begin{array}{c}\text { Weekend } \\
\text { (nontrading) }\end{array}$ & $\begin{array}{c}\text { Weekday } \\
\text { (trading) }\end{array}$ \\
1 (smallest) & 4505 & 0.939 & 0.885 \\
2 & 3430 & $(0.027)$ & $(0.021)$ \\
3 & 2479 & 0.992 & 0.924 \\
& & $(0.030)$ & $(0.028)$ \\
4 & 1757 & 0.958 & 0.931 \\
& & $(0.038)$ & $(0.033)$ \\
5 (largest) & 707 & 0.996 & 0.953 \\
& & $(0.034)$ & $(0.035)$ \\
& & 0.880 & 1.026 \\
& & $(0.061)$ & $(0.050)$ \\
\hline
\end{tabular}

\section{Summary and conclusions}

In this paper, we use a new approach to evaluate the flows of public and private information and their relation to short-run volatility. We analyze and compare the volatilities of returns during trading and nontrading periods, where nontrading periods are periods when exchanges and businesses are open but 
traders endogenously choose not to trade. In contrast, nontrading periods in previous studies coincide with exchange closings that are exogenously imposed and ex ante perfectly predictable.

Our definition of nontrading leads to several interesting findings. First, trading does not appear to be necessary to explain a significant proportion of the observed variance of stock returns once the returns have been adjusted for day-of-the-week effects, bid/ask bounce, and stickiness in quotes. An interesting aspect of the cross-sectional variation in the nontrading to trading ratios is that they are positively related to firm size: a significantly larger proportion of the return volatility of large firms occurs without trade. Given that large firms are actively followed by many market analysts, it may be easier for agents to decipher and agree upon the implications of certain types of public events for such firms. Therefore, prices of large firms may move more easily without trades.

Second, a detailed analysis of market microstructure effects and weekendto-weekday variance ratios using our definition of nontrading suggests that public information may be the major determinant of short-run volatility. [Harvey and Huang (1991) reach a similar conclusion regarding the volatility of foreign exchange rates]. For example, despite the existence of a statistically identifiable adverse-selection component in quoted spreads, the economic magnitude of this component appears to be small. Also, the adverse-selection component does not appear to vary between trading and nontrading days when exchanges and businesses are open, nor is it significantly higher following periods when markets are closed. Clearly, the results of each of the tests conducted in this paper could be consistent with more complex models of public and private information than the ones considered here. Nevertheless, when considered together, the evidence suggests that public information is the major source of short-run stock price volatility.

\section{Appendix}

This appendix is largely based on the analysis in Jones and Kaul (1993) and contains a brief discussion of potential biases in variance ratios and the procedures used to correct these biases.

\section{A.1. Effects of measurement errors on transaction-return-based variance ratios}

Suppose bid/ask errors are the only source of measurement errors in transaction prices. It is well known (see Roll, 1984) that the variance of observed (continuously-compounded) transaction returns, $R_{i t}^{t}$, is spuriously biased upward by $s_{i}^{2} / 2$, where $s_{i}$ is the proportional spread of the security. The use of transaction prices, however, also leads to biased estimators of the ratios of variances frequently used in the literature. Specifically, in the context of this 
paper, consider the weekend and weekday nontrading to trading variance ratios, $V_{1}$ and $V_{2}$ [see Eq. 3]. For simplicity, assume that all nontrading days are preceded by trading days. The measured variance ratios calculated from transaction prices can be written as

$$
V_{1}^{O}=\frac{\sigma_{i N T M}^{2}+\left(s_{i}^{2} / 4\right)}{\sigma_{i T M}^{2}+\left(s_{i}^{2} / 2\right)} \quad \text { and } \quad V_{2}^{O}=\frac{\sigma_{i N T T F}^{2}+\left(s_{i}^{2} / 4\right)}{\sigma_{i T T F}^{2}+\left(s_{i}^{2} / 2\right)}
$$

The spurious volatilities in the denominators of $V_{1}^{O}$ and $V_{2}^{O}$ are twice those in the numerators because of CRSP's policy of reporting transaction prices on trading days and the average of bid/ask quotes on nontrading days. Although both $V_{1}^{O}$ and $V_{2}^{O}$ will be biased toward 0.50 , the direction and magnitude of the bias is ambiguous because the bias is upward (downward) when the true unobservable ratios are less (greater) than 0.50 .

A potentially simple way to eliminate the noise in transaction returns due to bid/ask errors is to use the average of the closing bid/ask quotes of NASDAQNMS securities to calculate returns for both nontrading and trading days. Geraghty (1992), however, shows that NASDAQ market makers very frequently do not change quotes even if trades occur. To correct for the stickiness in quotes we therefore calculate an alternative set of estimates of all the variance ratios by conditioning the quote returns of each security on five lagged own returns and contemporaneous and five lagged returns of the market index [see (4) in Section 2.5].

\section{A.2. Bias adjustments for the median variance ratios}

There is an additional bias associated with the distribution of the variance ratio statistic. This bias results from the fact that the $F$-distribution presumed for variance ratios is sensitive to normality and the relative sample sizes of the numerator and denominator of the ratios. Specifically, the medians of the sampling distributions of the variance ratios will be biased downward if the sample sizes of the numerators are smaller than those of the denominators, and the extent of the bias is sensitive to the assumption of normality of returns. We therefore employ a resampling simulation technique inspired by the bootstrap method (see Efron and Tibshirani, 1986). Specifically, we estimate the bias by resampling under the null hypothesis that the true variances in the numerator and the denominator are equal. The departure of the simulated median variance ratios from unity provides an estimate of the bias in the median of the computed variance ratios.

The following brief discussion refers to the weekend nontrading to trading ratio; the procedure for the weekday ratio is analogous. For each firm, during each 126-trading-day subperiod we calculate the actual number of Monday nontrading and trading days, $N_{M N T}$ and $N_{M T}$, respectively. We then resample 
independently for each firm from its 126 squared residuals in a particular subperiod. The resampling is done with replacement $N_{M N T}$ times from the actual Mondays for the numerator and $N_{M T}$ times for the denominator, and we calculate the variance ratio based on the resampled values. We then calculate the median of the simulated variance ratios across all firms and subperiods. Medians calculated from 200 independent replications form the empirical cumulative density function (CDF) for the median statistic, under the assumption that the variances in the numerator and denominator are identical. We average the simulated cross-sectional medians and use these averages to correct for the downward bias in the sample medians. Specifically, median estimates reported in the paper are the uncorrected sample median estimates divided by the averages of the simulated medians. All simulations for the weekend-to-weekday (nontrading and trading) ratios reported in Table 7 are performed using similar but distinct algorithms (see Jones and Kaul, 1993).

\section{A.3. Calculation of the standard errors of the medians}

To conduct hypotheses tests on the bias-adjusted medians, we calculate standard deviations of the medians under the assumption that the true variances in the numerator and denominator are equal. We simulate the empirical CDF of each variance ratio by resampling with replacement from the 126 days, and do this once for each of 200 replications for each subperiod. For each security, we use the squared residuals and the trading/nontrading distinction on the resampled days to calculate the variance ratios (this helps account for any crosssectional correlation in the individual-firm variance ratios). The standard deviations of the empirical CDF's, however, are biased downward because the medians themselves are biased. We therefore adjust the standard deviations (upward) by dividing them by the same bias-correction factors that are used to adjust the median estimates.

Finally, the tests for the equality of the weekend-to-weekday trading and nontrading variance ratios are performed using a similar algorithm. The empirical CDF's of the two median variance ratios are calculated using the bootstrap technique described above. Statistical significance at level $\alpha$ for testing the equality of the median variance ratios then implies that $(1-\alpha / 2)$ of the independent replications resulted in $Q=V_{3}-V_{4}$ of the same sign.

\section{References}

Admati, Anat R. and Paul Pfleiderer, 1988, A theory of intraday trading patterns: Volume and price variability, Review of Financial Studies 1, 3-40.

Amihud, Yakov and Haim Mendelson, 1987, Trading mechanisms and stock returns: An empirical investigation. Journal of Finance 42, 533-553. 
Amihud, Yakov and Haim Mendelson, 1991, Volatility, efficiency and trading: Evidence from the Japanese stock market, Journal of Finance 46, 1765-1789.

Amihud, Yakov, Haim Mendelson, and Maurizio Murgia, 1990, Stock market microstructure and return volatility: Evidence from Italy, Journal of Banking and Finance 14, 423-440.

Barelay, Michael J., Robert H. Litzenberger, and Jerold B. Warner, 1990, Private information, trading volume, and stock-return variances, Review of Financial Studies 3, 233-253.

Blume, Marshall E. and Robert F. Stambaugh, 1983, Biases in computed returns: An application to the size-effect, Journal of Financial Economics 12, 387-404.

Christie, Andrew A., 1981, On efficient estimation and intra-week behavior of common stock variances, Working paper (University of Rochester, Rochester, NY).

Davidian, Marie and Raymond J. Carroll, 1987, Variance function estimation, Journal of the American Statistical Association 82, 1079-1091.

DeGroot, Morris E., 1989, Probability and statistics (Wesley Publishing Company, Reading, MA).

Easley, David and Maureen O'Hara, 1992, Time and the process of security price adjustment, Journal of Finance 47, 577-605.

Efron, Bradley and R. Tibshirani, 1986, Bootstrap methods for standard errors, confidence intervals, and other measures of statistical accuracy, Statistical Science 1, 54-77.

Fama, Eugene F., 1965, The behavior of stock market prices, Journal of Business 38, 34-105.

Foster, Douglas F. and S. Viswanathan, 1990, A theory of interday variations in volume, variance, and trading costs in securities markets, Review of Financial Studies 3, 593-624.

Foster, Douglas F. and S. Viswanathan, 1993a, Variations in trading volume, return volatility, and trading costs: Evidence on recent price formation models, Journal of Finance 48, $187-211$.

Foster, Douglas F. and S. Viswanathan, 1993b, The effect of public information and competition on trading volume and price volatility, Review of Financial Studies 6, 23-56.

French, Kenneth R., 1980, Stock returns and the weekend effect, Journal of Financial Economics 8, $55-69$.

French, Kenneth R. and Richard Roll, 1986, Stock return variances: The arrival of information and the reactions of traders, Journal of Financial Economics 17, 5-26.

George, Thomas J., Gautam Kaul, and M. Nimalendran, 1991, Estimation of the bid-ask spread and its components: A new approach, Review of Financial Studies 4, 623-656.

Geraghty, Kevin M., 1992, Stickiness in NASDAQ dealer quotes, Working paper (University of Chicago, Chicago, IL).

Glosten, Lawrence R., 1987, Components of the bid-ask spread and the statistical properties of transaction prices, Journal of Finance 42, 1293-1308.

Glosten, Lawrence R. and Paul R. Milgrom, 1985, Bid, ask and transaction prices in a specialist market with heterogeneously informed traders, Journal of Financial Economics 14, 71-100.

Granger, Clive W.J. and Oskar Morgenstern, 1970, Predictability of stock market prices (HeathLexington, Lexington, MA).

Harris, Milton and Artur Raviv, 1993, Differences of opinion make a horse race, Review of Financial Studies 6, 473-506.

Harvey, Campbell R. and Roger D. Huang, 1991, Volatility in foreign currency futures markets, Review of Financial Studies 4, 543-569.

Hasbrouck, Joel, 1991, The summary informativeness of stock trades: An econometric analysis, Review of Financial Studies 4, 571-595.

Jones, Charles M., 1993, Transaction costs and short-term return predictability, Working paper (University of Michigan, Ann Arbor, MI).

Jones, Charles M. and Gautam Kaul, 1993, On the use of variance ratios, Working paper (University of Michigan, Ann Arbor, MI).

Jones, Charles M., Gautam Kaul, and Marc L. Lipson, 1993, Transactions, volume and volatility, Working paper (University of Michigan. Ann Arbor, MI). 
Kaul, Gautam and M. Nimalendran, 1990, Price reversals: Bid-ask errors or market overreaction?, Journal of Financial Economics 28, 67-93.

Keim, Donald B., 1989, Trading patterns, bid-ask spreads, and estimated security returns: The case of common stocks at calendar turning points, Journal of Financial Economics 25, 75-97.

Keim, Donald B. and Robert F. Stambaugh, 1984, A further investigation of the weekend effect in stock returns, Journal of Finance 39, 819-835.

Kim, Oliver and Robert E. Verrecchia, 1991, Market reaction to anticipated announcements, Journal of Financial Economics 30, 273-309.

King. Ronald, Grace Pownall, and Gregory Waymire, 1991, Corporate disclosure and price discovery associated with NYSE temporary trading halts, Contemporary Accounting Research $8,509-531$.

Kyle, Albert S., 1985, Continuous auctions and insider trading, Econometrica 53, 1315-1335.

Merrington, Maxine and Catherine M. Thompson, 1943, Tables of the percentage points of the inverted beta $(\mathrm{F})$ distribution, Biometrika 33, 73 .

Oldfield, George S.. Jr. and Richard J. Rogalski, 1980. A theory of common stock returns over trading and nontrading periods, Journal of Finance 35, 729751.

Pagan, Adrian R. and G. William Schwert, 1990, Alternative models for conditional stock volatility, Journal of Econometrics 45, 267-290.

Roll, Richard, 1984, A simple implicit measure of the bid-ask spread in an efficient market, Journal of Finance 39, 1127-1139.

Schwert, G. William, 1990, Stock volatility and the crash of '87, Review of Financial Studies 3, $77-102$.

Slezak, Steve L., 1992, The behavior of asset return moments with asymmetric information, price taking and risk aversion, Working paper (University of Michigan, Ann Arbor, MI).

Stoll, Hans R., 1989, Inferring the components of the hid-ask spread: Theory and empirical tests. Journal of Finance 44, 115-34.

Stoll, Hans R. and Robert E. Whaley, 1990, Stock market structure and volatility, Review of Financial Studies 3, 37-71.

Varian, Hal R., 1989, Differences of opinion in financial markets, in: Courtenay C. Stone, ed., Financial risk: Theory, evidence and implications, Proceedings of the Eleventh Annual Economic Policy Conference of the Federal Reserve Bank of St. Louis (Kluwer Academic Publishers, Boston, MAI 3-37. 